\title{
Knowledge and Self-Practice of Pharmacists and Prescribers Towards The Uses of Generic Drugs In Community Settings in Belagavi, Karnataka, INDIA
}

\author{
Rawat Rashmilata1, Ganachari Madiwalayya Shivakantayya ${ }^{2}$, Salimath Geetanjali ${ }^{3}$ \\ ${ }^{1}$ Pharmacy Practice, KLEU's College of Pharmacy, Belagavi, Karnataka,INDIA. \\ ${ }^{2} \mathrm{Head}$ of the Pharmacy Practice Department, KLEU's College of pharmacy, Belagavi, Karnataka, INDIA. \\ ${ }^{3}$ Pharmacy Practice, KLEU's College of pharmacy, Belagavi, Karnataka, INDIA.
}

\begin{abstract}
Background: To increase the knowledge of health professionals towards generic drugs so that they increase the practice of using generic drugs in their daily routine. Aims: To evaluate/investigate the Knowledge and selfpractice of Pharmacists, Prescribers regarding Generic Drug (GD) Use. Settings and Design: A community based quasi experimental study. Methods and Material: Validated Pre self-administered questionnaires for Pharmacists and Physicians were prepared. In between educational workshop and Information leaflet were provided. Post questionnaires were given to both health professionals and consumers to assess their awareness and were asked to answer the questionnaires' used during pre-survey. Data was collected by completing the informative questionnaires. Statistical Analysis: Scores were analysed using software SPSS, version 30.0. Results: 183 Physicians and Pharmacists were participated, 146 were community pharmacists and 37 were physicians. 125 $(85.62 \%)$ pharmacists, $31(83.78 \%)$ physicians were believed that GDs are therapeutically bio equivalent to innovator drugs. 123 (84.24\%) Pharmacists, 25 (67.57\%) physicians agreed that GDs contain the same active ingredients and treat the same disease at the same dose compare to brand name drug. Among the participants, $127(86.99 \%)$ pharmacists have stored GDs at their stores. Majority of 37 physicians preferred prescribing GDs. Conclusions: This study, Knowledge and self-practice of Pharmacists and Prescribers towards the uses of Generic drugs in community settings found acceptable awareness among general population that reduces the cost of health expenditure and improves quality of life. The counselling and education improved the perception of pharmacists and prescribers towards Generic drug use.
\end{abstract}

Key words: Knowledge, Practice, Health professionals, Generic drugs, Pharmacists, Prescribers, Community.

\section{INTRODUCTION}

In developing countries, due to without interruption ongoing innovations in medical field or demand of treating many chronic diseases with drugs, hence it is difficult to provide sufficient pharmacotherapy, the cost of the health expenses increases each year in aging population. ${ }^{1,2}$ Now a day's branded medicines are accomplished by Multi-National Companies. Physicians and chemists are the main source of assisting Generic drugs and that promotion amount add to their retail prices i.e., Maximum Retail Price (MRPs). This unethical promotion by the companies to common man may create ineffable essential medicines. ${ }^{3}$

DOI: 10.5530/ijopp.9.4.2

Generic drugs (GD) are bioequivalent in dosage, form, safety, strength, route of administration, quality, performance characteristics and intended use to innovator drugs. ${ }^{4}$ Although generic medicines are an affable alternative to the highly priced patented brand namedrug. ${ }^{5}$

Generic Drugs or International Non-proprietary Name (INN) is a Pharmaceutical product that is intended to be exchangeable with a brand medicine, made from the branded company without a licence,
Address for correspondence:

Rashmilata Rawat, M.Pharm, Pharmacy Practice, KLE College of Pharmacy, Nehru Nagar - Belagavi, Karnataka, India.

Phone no: 09902701205

E-mail: rashrawat0121@gmail. com

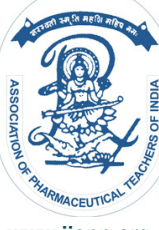

www.ijopp.org 
marketed after the expiry date of the patent of innovator drug. ${ }^{6}$

After expiry of the innovator product's patent term protection, other manufacturing companies submit their file to regulatory authorities for approval to market generic versions of the originator medicine. Generic drugs may be marketed under branded generic. Branded generic drugs have names derived from a combination of the manufacturer's name and the non-proprietary name. This enables the manufacturer to market the product in a way similar to the proprietary product. ${ }^{7}$ Generic drugs are cheaper in comparison to branded drugs because there is no need to make investments in Research and Development as in the case of new drugs. ${ }^{8}$

Both branded and generic drugs are manufactured by conforming to International standards. Brand name drugs are usually given patent protection for 20 years from the date of submission of the patent. This provides protection for the innovator of such drugs to make good the initial costs incurred by him, viz., and research development, to develop the new drug. Many drug companies start manufacturing generic drugs once the patent license expires for a branded drug. Patients should become assertive and insist upon the doctors to prescribe generic drugs if available, so that the patient would get the product at the best possible price. Pharmacists also play a vital role in educating the doctors about the availability of generic drugs. Thus the right medication could be given to the patients at the best possible price. ${ }^{9}$ The essential drug concept adopted in many developing countries promotes use of generic medicines, the main reason for generics is drug price containment through competition to improve access to essential medicines. ${ }^{10}$

In 201l, $\$ 192.8$ billion saving was found after Intercontinental Marketing Services Institute (IMS) conducted savings study generic drug. Over the past 10 years, $\$ 481$ billion savings from generic medicines for those that have entered the market since 2002 in developing countries like India the generic drugs are not widely in used and the awareness about generic drugs both in prescribers and in patients are not well. ${ }^{11,12}$

To ensure effective improvement under Drug Price Control Order (DPCO) 1995then in 1997, the Government of India constituted a body of experts known as 'National Pharmaceutical Pricing Authority' (NPPA), which works under the Department of Pharmaceuticals (DoP).This department had made the responsibilities of drug policy, medicine price control, monitoring of drug prices for the affordability and availability of the generic medicine to a common man and in rural area. In April 2008, Government of India had launched the 'Jan Aushadhi Scheme' for better availability of low cost generic medicines. They opened the public generic drug store in each state in which various state governments that provided space free of charge of generic medicine to public hospitals. ${ }^{13}$

In 29 February 2016, the financial minister of India, Mr. Arun Jatley recently presented the budget in which he emphasized on the better availability of generic drugs especially to the poor people of rural areas. Further he also announced the start-up of around 3000 Jan Aushadhi stores all over India under prime minister Jan Aushadhi yojana during 2016-17 which approximately brings about the startup of at least 5 stores per district. ${ }^{14}$

\section{MATERIAL AND METHODS}

A community based quasi-experimental study was conducted from September 2015 to April 2016 in rural area (Kakati, Honaga, Mache, Hind alga), Belagavi, Karnataka, INDIA.

\section{Ethical Clearance}

The study obtained clearance from the Institutional Ethics Committee of the concerned medical education Institute.

The different Pre and Post questionnaires were prepared for Physicians and Pharmacists respectively. The questionnaires were validated by 02 Physicians, 03 Pharmacists. Pilot study was also done to understand the knowledge and practice of Generic drugs among Physicians and Pharmacists.

The questionnaire consisted of 10 questions divided into two sections. Section1 knowledge based and section 2 practice based. The Pre-questionnaires were given to pharmacists and physicians. After taking feedback from the participants, an education was given to them regarding generic drugs. They were counselled, educated, encouraged, provided information leaflet and date of their next follow-up was noted. Participants were enquired for their awareness and were asked to answer the questionnaires' used during pre-survey. Data was collected by completing the informative questionnaires.

\section{Statistical Analysis}

The data were transferred to Microsoft excel. Statistical analysis was performed using software SPSS, version 30.0. Paired t-test between percent was used 
to compare the responses. $P$-Values of $<0.05$ were considered to indicate statistical significant.

\section{RESULTS}

In this study total 183 participants were participated, in which 146 were community pharmacists and 37 were physicians. The study was conducted for a total duration of 8 months.

Comparison of Knowledge and Practice of Pharmacists, Physicians by Pre and Post Assessment Survey:

The below mentioned (Table 1) comprises of the response (\%) to the pre and post assessment survey of pharmacists and physicians towards knowledge and practice towards generic drug use in which among 10 questionnaires, 05 were already segregated each for knowledge and practice.

\section{*Pharmacists}

Q1- Every generic medicine is therapeutically bioequivalent to brand medicine?, Q2-A generic medicine contains the same active substances as the brand medicine and used at the same dose to treat the same disease as brand drug?, Q3-Are you aware of regarding the scheme of Government of India called 'JAN AUSHADHI' whose purpose is to set up generic drug store around the country?, Q4-Generic medicine can be only marketed after the expiry date of the patent of innovator?, Q5-Generic medicine produces more side effects compared to brand medicine?,Q6In your Pharmacy, do you store Generic drugs?, Q7-In your daily practice, it is more convenient to remember branded medicine name?, Q8-Do you use substitution in all cases where Generic medicines are available?, Q9- Switching a patient from brand medicine to Generic medicine may change the outcome

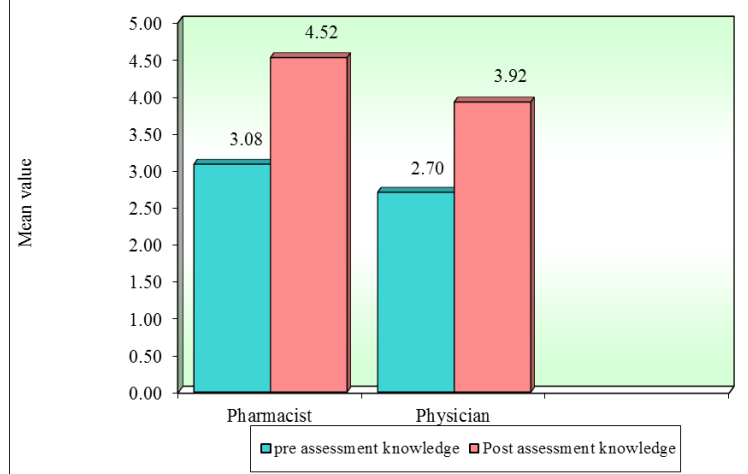

Figure 1: Comparison of Pre Assessment and Post Assessment Knowledge scores of pharmacists and physicians. of the therapy?, Q10-Do you use substitution in all cases where Generic medicines are available?.

\section{Physicians}

Q1-Every generic medicine is therapeutically bioequivalent to brand medicine?, Q2-A generic medicine contains the same active substances as the brand medicine and used at the same dose to treat the same disease as brand drug?, Q3-Are you aware of regarding the scheme of Government of India called ' $A A N$ AUSHADHI' whose purpose is to set up generic drug store around the country?,Q4-Generic antibiotic are less effective than the brand antibiotics?, Q5- Generic medicine produces more side effects compared to brand medicine?, Q6-Do you prescribe Generic medicine in your daily practice?,Q7-In your daily practice, it is more convenient to remember branded medicine name?, Q8-In case of value perception, fear of losing patients through Generic prescribing?,Q9- Switching a patient from brand medicine to Generic medicine may change the outcome of the therapy?,Q10-Do you use substitution in all cases where Generic medicines are available?

\section{Knowledge}

125(85.62\%) pharmacists and 31(83.78\%) physicians believed that every generic drugs are therapeutically bioequivalent to brand medicine. 123(84.25\%) Pharmacists and 25 (67.57\%) Physicians knew that generic drugs contains same active substances and used at the same dose to treat the same disease as brand drug. 121(82.88\%) Pharmacists and 28(75.68\%) Physicians do not believe that Generic medicine produces more side effects compared to brand medicine. Comparison between pre and post assessment of Knowledge were 3.08 and 4.52 for Pharmacist, 2.70 and 3.92 for Physicians respectively (Figure 1). Statistically significant differences in knowledge were observed after

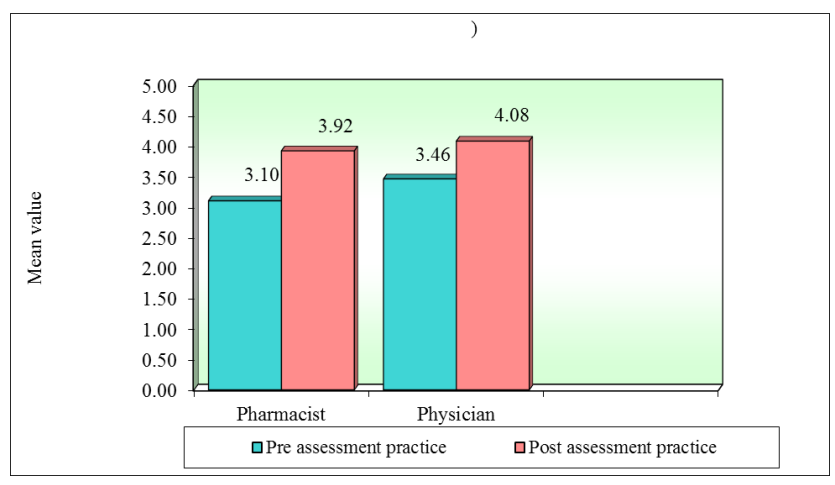

Figure 2: Comparison of pre assessment and post assessment Practice scores of pharmacists and physicians. 


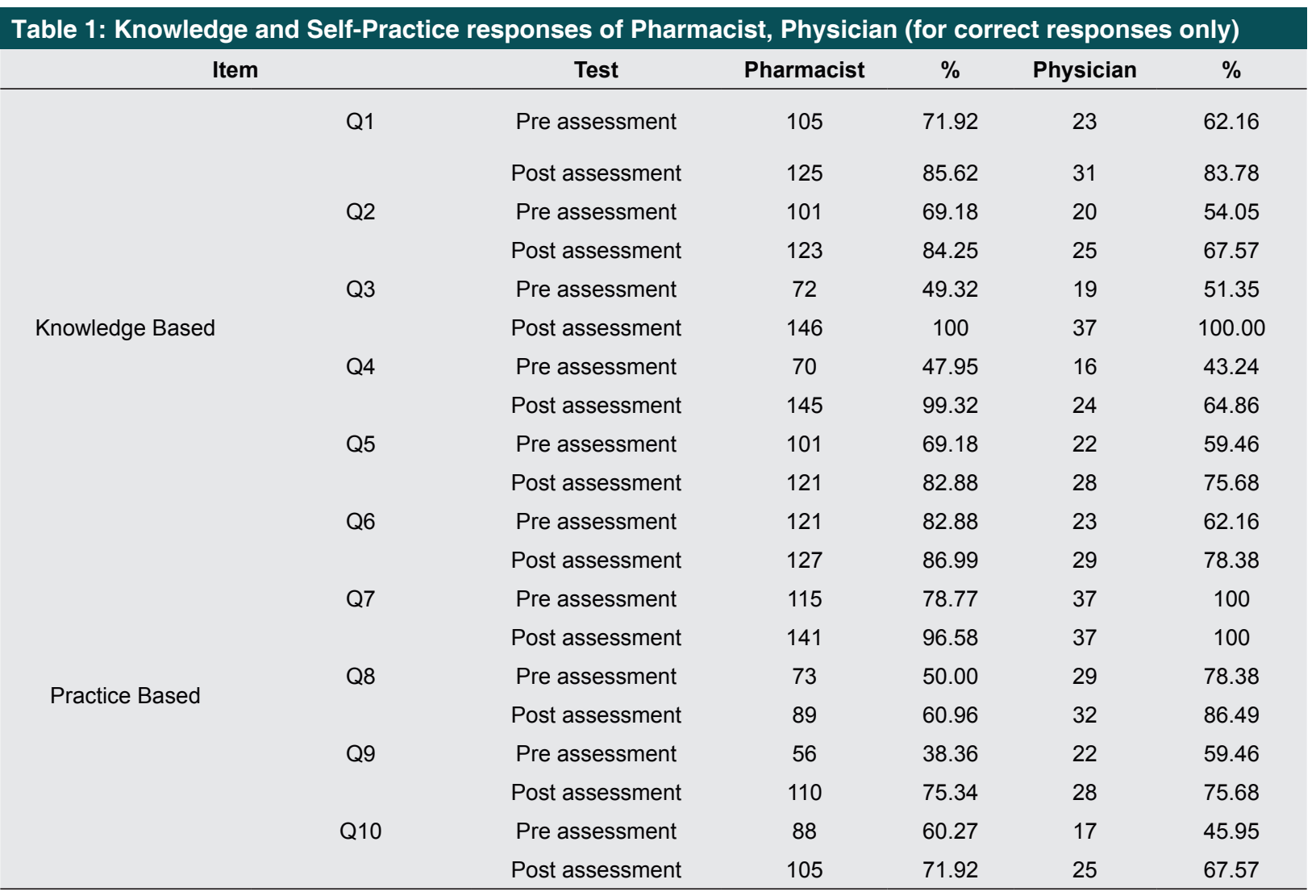

\section{Table 2: Comparison of pre assessment and post assessment Knowledge of Pharmacist and Physician}

\begin{tabular}{ccccccccc} 
Groups & Time & Mean & Std. Dv. & $\begin{array}{c}\text { Mean } \\
\text { Diff. }\end{array}$ & $\begin{array}{c}\text { SD } \\
\text { Diff. }\end{array}$ & $\begin{array}{c}\% \text { of } \\
\text { change }\end{array}$ & Paired t test & p-value \\
\hline Pharmacist & Pre-assess & 3.08 & 1.26 & & & & & \\
& post assess & 4.52 & 0.63 & -1.45 & 1.03 & -46.99 & -16.9411 & $0.0001^{*}$ \\
\multirow{2}{*}{ Physician } & Pre-assess & 2.70 & 1.47 & & & & & \\
& post assess & 3.92 & 0.98 & -1.22 & 1.27 & -45.00 & -5.8149 & $0.0001^{*}$ \\
\hline$p<0.05$ & & & & & & & &
\end{tabular}

\begin{tabular}{|c|c|c|c|c|c|c|c|c|}
\hline Groups & Time & Mean & $\begin{array}{l}\text { Std. } \\
\text { Dv. }\end{array}$ & $\begin{array}{c}\text { Mean } \\
\text { Diff. }\end{array}$ & $\begin{array}{l}\text { SD } \\
\text { Diff. }\end{array}$ & $\begin{array}{c}\% \text { of } \\
\text { change }\end{array}$ & $\begin{array}{c}\text { Paired } \\
t \text { test }\end{array}$ & p-value \\
\hline \multirow[t]{2}{*}{ Pharmacist } & Pre-assess & 3.10 & 1.14 & & & & & \\
\hline & post assess & 3.92 & 0.91 & -0.82 & 0.81 & -26.27 & -12.2314 & $0.0001^{*}$ \\
\hline \multirow[t]{2}{*}{ Physician } & Pre-assess & 3.46 & 1.22 & & & & & \\
\hline & post assess & 4.08 & 0.98 & -0.62 & 0.83 & -17.97 & -4.5646 & $0.0001^{*}$ \\
\hline
\end{tabular}

pre and post assessment knowledge in Pharmacists and Physicians (Table 2).

\section{Practice}

$127(86.99 \%)$ pharmacists' stores Generic drugs in their pharmacy. 29(78.38\%) physicians prescribe Generic medicine in their daily practice. $110(75.34 \%)$
Pharmacists and 28(75.68\%) Physicians do not believe that switching a patient from brand medicine to Generic medicine may change the outcome of the therapy. Comparison between pre and post assessment of practice were 3.10 and 3.92 for Pharmacist, 3.46 and 4.08 for Physicians, respectively (Figure 2). Statistically significant differences in practice were 
observed after pre and post assessment practice in Pharmacists and Physicians (Table 3).

\section{DISCUSSION}

The moral responsibility of the health professionals to enhance awareness regarding high quality health care system among population by increasing usage of generic medicines improve affordability and availability without compromising with quality. The study showed that the participants awareness regarding Generic drugs were increased more towards their knowledge and daily practice. It was evident from the study that participants' perceptions and acceptance of existing Jan Aushadhi services and easy availability of branded Generic drugs into market has been enhanced. A similar study showed same result by Lopes Gde L. et al. among physicians in India. Physicians were agreed that generic drugs can reduce health expenditure along with lower price of the generic drugs. In Indian the cost of generic drugs is $91 \%$ less the innovator medicine. Most of the physician only prescribed in greater extent and found greater trust toward generic drugs and they prescribed them to a greater degree. ${ }^{15}$

Other hands, Chong et al. conducted a cross section National descriptive study on Pharmacists practices regarding Generic drugs in Australia's rural, remote and urban area in 2011. This study came out with the following conclusion that the acceptance of the Generic drugs by Pharmacists may also improve the perception of consumers towards Generic drug uses. $^{16}$

It was encouraging that all the participants including Pharmacist and Physicians recognized towards good quality, safety and efficacy by educational services of Generic drugs. This finding of participants is specific to their knowledge and perception and the experience would be different in participants.

A similar study by Dunne et al. who conducted a survey on perception of Generic medicines among 34 General practitioners and 44 Community Pharmacists in Ireland in 2014. Education of participants is require to increase the use of Generic drugs and needed of some resources that facilitate healthcare professionals to educate consumers. ${ }^{17}$

The study has some important limitations as followsGeneral belief: There is a general belief among the participants that since the generic drugs are Cheaper than the materials used to formulate them will also be cheaper and hence low in quality and also might have various side effects. This is why it was difficult to convince them towards the usage of generic drugs,
Past experiences: Some of the physicians, pharmacist had negative experiences with respect to generic Drug substitutions and hence they were further not ready to accept as well as consult and counsel for the use of generic drugs, Lack of Time: This study could not evaluate the experience of some of the participants because of their lack of time, interest and busy schedule. Study could not conduct in illiterate population because limited time period.

\section{CONCLUSION}

The study concluded that there was statistically significant improvement in knowledge and selfpractices of Generic Drugs in pharmacists, prescribers towards consumer's better health. Generic drug awareness among general population reduces the cost of health expenditure and improves quality of life. The counselling and education improved the perception of pharmacists and prescribers towards Generic drug use.

\section{AKNOWLEDGEMENT}

I would like to express thanks to KLE's Dr. Prabhakar hospital and Medical Research Center Head of Pharmacy Practice Department Dr. M.S. Ganachari, Mrs. Geetanjali Salimath, Dr. Prashant Mathur for their support and the two anonymous reviewers.

\section{CONFLICT OF INTEREST}

No conflict of interest are declared.

\section{ABBREVIATION USED}

GDs: Generic Drugs; MRPs: Maximum Retail Prices; INN: International Non-proprietary Name; IMSI: Intercontinental Marketing Services Institute; DPCO: Drug Price Control Order; NPPA: National Pharmaceutical Pricing Authority; DoP: Department of Pharmaceuticals; KLEs: Karnataka Lingayat Education.

\section{REFERENCES}

1. Shrank WH, Choudhry NK, Liberman JN, Brennan TA. The use of generic drugs in prevention of chronic disease is far more cost-effective than thought, and may save money. Health Aff (Millwood). 2011;30(7):1351-57. http://dx.doi. org/10.1377/hlthaff.2010.0431; PMid:21734210.

2. Pechlivanoglou P, van der Veen WJ, Bos JH, Postma MJ. Analyzing generic and branded substitution patterns in the Netherlands using prescription data, BMC Health Serv Res. 2011;11(1):89 http://dx.doi.org/10.1186/1472-6963-1189 ; PMid:21524312 PMCid:PMC3107776.

3. Wazana A. Prescribers and the Pharmaceutical Industry: Is a gift ever just a gift?. JAMA. 2000;283(3):373-80. http://dx.doi.org/10.1001/jama.283.3.373; PMid:10647801. 
4. U.S. Food and Drug Administration. Available from: http://www.fda.gov/ drugs/resourcesforyou/consumers/buying using medicinesafely/understand inggeneric drugs/default.htm

5. Joncheere K, Rietveld AH, Huttin C. Experiences with generics. In: M.N.G Dukes, F.M. Haaijer-Ruskamp, C.P. Joncheere and A.H. Rietveld (eds.) Drugs and Money, 7th edn.(2002) The Netherlands: Published on behalf of WHOEurope, IOS Press, 101-10.

6. Generic drugs. http://www.who.int/trade/glossary/story034/en/index.ht

7. King DR, Kanavos P. Encouraging the use of generic medicines: implications for transition economics. Croat Med J. 2002;43(4):462-9. PMid:12187525.

8. Dadhich A, Upadhyaya M. A review: exploring branded generic drugs by Indian pharmaceutical multinational companies as a new prospect. Pharmacophore. $2011 ; 2(6): 271-5$.

9. Bakthavathsalam G. Generic drugs: Cost effective alternative to branded drugs. Health Adm. 9(1):16-9

10. Olusola AM, Olubukola OO, Emeka OH, Lilian AE. Equivalence of two generic brands of amlodipine besylate under biowaiver conditions. Int J Pharmacy Pharm Sci. 2012;4(2):265-8.

11. Davit BM, Nwakama PE, Buehler GJ, Conner DP, Haidar SH, Patel DT, et al. Comparing generic and innovator drugs: a review of 12 years of bioequivalence data from the United States Food and Drug Administration. Ann Pharmacother. 2009;43(10):1583-97. http://dx.doi.org/10.1345/aph.1M141; PMid:19776300.

12. Centers for Medicare and Medicaid Services (2012, April 11). National Health CareExpenditure Data.Retrieved June 1, 2012, from https://www.cms.gov/ Research-Statistics-Data-and-Systems/Statistics-Trends-and Reports/National Health Expend Data.

13. Department of Pharmaceuticals. (2009) Ministry of chemicals and fertilizers. Government of India, http://pharmaceuticals.gov.in.

14. Union Budget 2016-17, http://indiabudget.nic.in/glance.asp, 29 February 2016.

15. Lopes Gde L. Cost comparison and economic implications of commonly used originator and generic chemotherapy drugs in India. Ann Oncol. 2013;24(5):136. http://dx.doi.org/10.1093/annonc/mdt323; PMid:23975699.

16. Chong CP, March G, Clark A, Gilbert A, Hassali MA. A nationwide study on generic medicines substitution practices of Australian community pharmacists and patient acceptance. Health Policy (New York). Elsevier Ireland Ltd. 2011;99(2):139-48

17. Dunne S, Shannon B, Hannigan A, Dunne C, Cullen W. Physician and pharmacist perceptions of generic medicines: What they think and how they differ. Health Policy (New York). Elsevier Ireland Ltd. 2014;116(2):214-23. 